\title{
DETAILED VALIDATION OF AMSR2 SEA ICE CONCENTRATION DATA USING MODIS DATA IN THE SEA OF OKHOTSK
}

\author{
K. Cho ${ }^{1 *}, \mathrm{~K}_{\text {. Naoki }}{ }^{1}$, J. Comiso ${ }^{2}$ \\ ${ }^{1}$ Tokai University, 4-1-1 Kitakaname Hiratsuka, Kanagawa 259-1292, Japan (kohei.cho, naoki)@tokai-u.jp \\ ${ }^{2}$ Cryospheric Sciences Laboratory, NASA Goddard Space Flight Center, Greenbelt, Maryland, USA - Josefino.C.Comiso@nasa.gov
}

\section{Commission III, WG III/9}

KEY WORDS: passive microwave radiometer, Bootstrap Algorithm, global warming, GCOM-W

\begin{abstract}
:
Global warming is one of the most serious problems we are facing in the 21st Century. Sea ice has an important role of reflecting the solar radiation back into space. However, once sea ice started to melt, the ice-free water would absorb the solar radiation and amplify global warming in the Arctic region. Thus, importance of sea ice monitoring is increasing. Since longer wavelength microwave can penetrate clouds, passive microwave radiometers on-board satellites are powerful tools for monitoring the global distribution of sea ice on daily basis. The Advanced Passive Microwave Scanning Radiometer AMSR2 which was launched by JAXA in May 2012 onboard GCOM-W satellite provides brightness temperature data that are used to estimate sea ice concentration, the fundamental parameter that is used to monitor the sea ice cover. JAXA is providing AMSR2 sea ice concentration data, derived using ASMR2 Bootstrap Algorithm as a standard product of AMSR2, as a means to communicate how the sea ice cover is changing. This paper describes the advantages of AMSR2 in calculating sea ice concentration and evaluate the accuracy of the sea ice concentration in the Sea of Okhotsk by comparing the result with simultaneously collected MODIS data. The result suggested that under normal winter condition, the RMSE of the AMSR2 sea ice concentration could be less than $10 \%$.
\end{abstract}

\section{INTRODUCTION}

The global average surface temperature in 2019 was $+0.79{ }^{\circ} \mathrm{C}$ above the $20^{\text {th }}$ century average, and was second warmest since 1981 (JMA, 2020). Figure 1 shows the annual anomalies of global average surface temperature since 1891. Global warming is one of the most serious problems we are facing in the $21^{\text {st }}$ Century. Since sea ice is quite sensitive to global warming, the importance of sea ice monitoring is increasing.

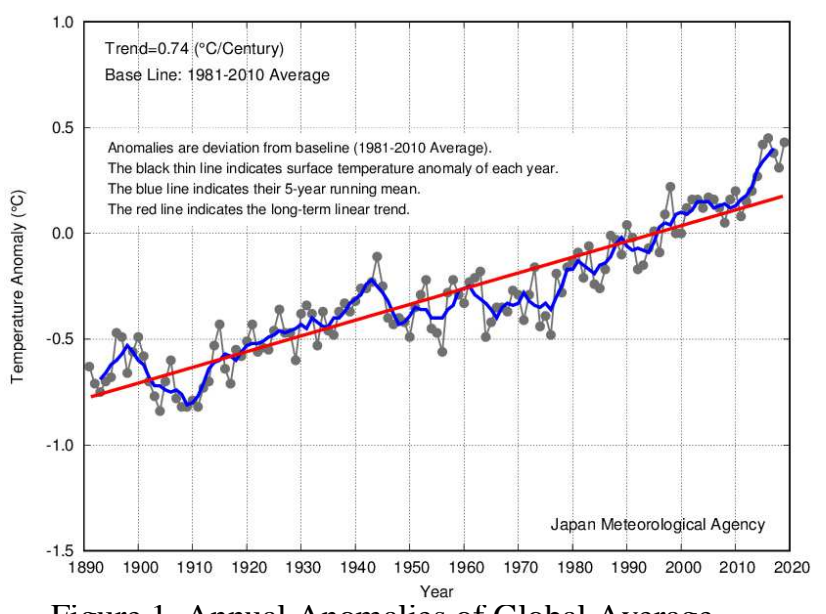

Figure 1. Annual Anomalies of Global Average Surface Temperature (1891 - 2019) (After JMA, 2020)
The global sea ice observation from space using passive microwave radiometers started in 1978 by SMMR onboard Nimbus-7 satellite. Since then, a series of passive microwave radiometers including SSM/I and AMSR have been continuously observing various global phenomena including sea ice from space as shown on Table 1. Since longer wavelength microwave can penetrate clouds, passive microwave radiometers on-board satellites are powerful tools for monitoring the global distribution of sea ice on a daily basis.

Table 1. Passive microwave radiometers which have been used for long time sea ice monitoring.

\begin{tabular}{|l|c|c|c|}
\hline \multicolumn{1}{|c|}{$\begin{array}{c}\text { Operation } \\
\text { period }\end{array}$} & Satellite & Sensor & Operator \\
\hline $\begin{array}{l}\text { Oct. 1978- } \\
\text { Aug. 1987 }\end{array}$ & Nimbus7 & SMMR & NASA \\
\hline July, 1987- & $\begin{array}{l}\text { DMSP } \\
\text { Series }\end{array}$ & SSM/I & $\begin{array}{c}\text { US Air force } \\
\text { /NOAA } \\
\text { /NASA }\end{array}$ \\
\hline $\begin{array}{l}\text { Dec. 2002- } \\
\text { Oct.2003 }\end{array}$ & ADEOS II & AMSR & JAXA \\
\hline $\begin{array}{l}\text { May, 2002- } \\
\text { Nov. 2011 }\end{array}$ & Aqua & AMSR-E & JAXA \\
\hline May, 2012- & GCOM-W & AMSR2 & JAXA \\
\hline
\end{tabular}

\footnotetext{
*Corresponding author: Kohei Cho, Tokai University Research \& Information Center, 2-3-23, Takanawa, Minato-ku, Tokyo, 108-8619, Japan
} 
Figure 2 shows the interannual variability of sea ice extent of the northern hemisphere derived from the continuous observation of passive microwave radiometers (JAXA, NIPR, 2020). The steep vertical movement of the graph show the annual pattern of the sea ice area which increases in winter and decreases in summer. The negative trend of sea ice area in the Northern Hemisphere is clear, especially in summer when the extent was reduced from about $8 \times 10^{6}$ to about $4 \times 10^{6} \mathrm{~km}^{2}$.

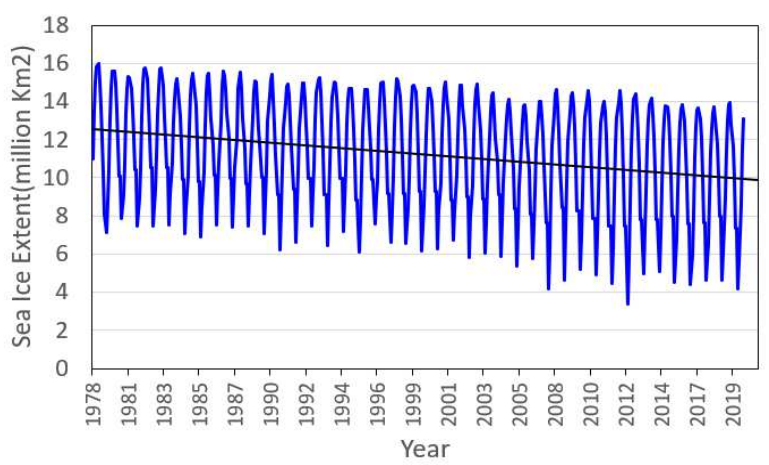

Figure 2. Interannual variability of sea ice area in the Northern Hemisphere derived from satellite passive microwave observations.

(JAXA, NIPR, 2020)

\section{ANALYZED DATA}

\subsection{AMSR2 Sea Ice Concentration Data}

The passive microwave radiometer AMSR2 was launched by JAXA in May 2012 on-board GCOM-W satellite (JAXA 2012). The antenna diameter of AMSR2 is $2.0 \mathrm{~m}$ which provide the highest spatial resolution among passive microwave radiometers in space. Table 2 show the specifications of AMSR2. In this study, AMSR2 sea ice concentration data with the spatial resolution (IFOV) of $25 \mathrm{~km}$ was analysed. Ice concentration is the most fundamental parameters of sea ice which can be calculated from brightness temperatures measured by passive microwave radiometers. As for AMSR2, JAXA is using AMSR Bootstrap Algorithm (Comiso et al., 2009, 2013) as the standard algorithm for calculating sea ice concentration from AMSR2 data.

Table 2. Specifications of AMSR2

\begin{tabular}{|c|c|c|c|}
\hline $\begin{array}{c}\text { Frequency } \\
\text { (polarization) }\end{array}$ & IFOV & Swath & $\begin{array}{c}\text { Incident } \\
\text { angle }\end{array}$ \\
\cline { 1 - 2 } $6.925 \mathrm{GHz}(\mathrm{V}, \mathrm{H})$ & $35 \times 62 \mathrm{~km}$ & & \\
\cline { 1 - 2 } $10.65 \mathrm{GHz}(\mathrm{V}, \mathrm{H})$ & $24 \times 42 \mathrm{~km}$ & & \\
\cline { 1 - 2 } $18.7 \mathrm{GHz}(\mathrm{V}, \mathrm{H})$ & $14 \times 22 \mathrm{~km}$ & \multirow{2}{*}{$\begin{array}{c}140 \\
\mathrm{~km}\end{array}$} & $55 \mathrm{deg}$ \\
\cline { 1 - 2 } $23.8 \mathrm{GHz}(\mathrm{V}, \mathrm{H})$ & $15 \times 26 \mathrm{~km}$ & & \\
\cline { 1 - 2 } $36.5 \mathrm{GHz}(\mathrm{V}, \mathrm{H})$ & $7 \times 12 \mathrm{~km}$ & & \\
\cline { 1 - 2 } $89.0 \mathrm{GHz}(\mathrm{V}, \mathrm{H})$ & $3 \times 5 \mathrm{~km}$ & & \\
\hline
\end{tabular}

Table 3. Specification of MODIS

\begin{tabular}{|c|c|c|c|}
\hline Band & Wavelength & IFOV & Swath \\
\hline 1 & $0.620-0.670 \mu \mathrm{m}$ & \multirow{2}{*}{$250 \mathrm{~m}$} & \multirow{2}{*}{$2330 \mathrm{~km}$} \\
\cline { 1 - 2 } 2 & $0.841-0.876 \mu \mathrm{m}$ & & \\
\hline
\end{tabular}

Figure 3 shows the schematic diagram of calculating ice concentration (IC) in the AMSR2 Bootstrap Algorithm. When we plot AMSR2 brightness temperature data on the scatter plot of $37 \mathrm{GHz}$ Vertical polarization (V) vs $19 \mathrm{GHz}$ Horizontal polarization $(\mathrm{H})$, Open water $(\mathrm{IC}=0 \%)$ comes to around point $\mathrm{R}$ and $100 \%$ sea ice cover distribute around the line PQ. Let us assume that the AMSR2 brightness temperatures of certain sea ice area is plotted on point $\mathrm{S}$ in Figure 3. We extent the line RS and find the cross point $\mathrm{F}$ with line PQ. Then, the ice concentration IC of the sea ice area can be calculated with the following equation.

$\mathrm{IC}=\mathrm{m} / \mathrm{n}$

where $\mathrm{m}$ : length of line SR,

$\mathrm{n}$ : length of line FR

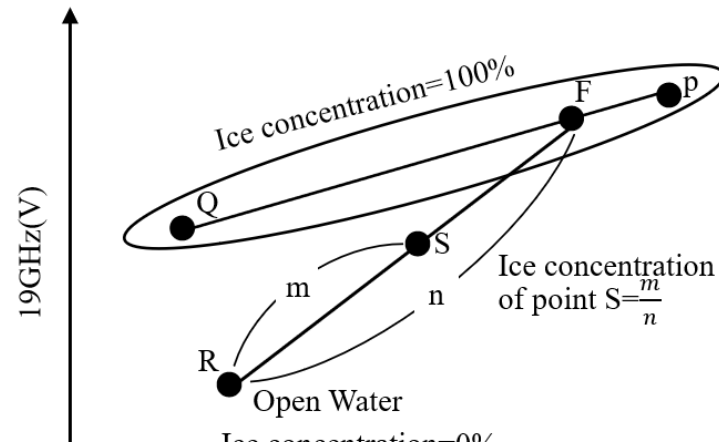

Ice concentration $=0 \%$

$37 \mathrm{GHz}(\mathrm{V})$

Figure 3. Schematic diagram of calculating sea ice concentration in the AMSR Bootstrap Algorithm

Figure 4 shows the comparison of SSM/I and AMSR2 ice concentration images of Arctic observed on July 27, 2013. The ice concentration of SSM/I data were calculated with Bootstrap Algorithm (Comiso, 1995). According to the spatial resolution advantage of AMSR2 against SSM/I, much detailed sea ice distribution can be observed with AMSR2.

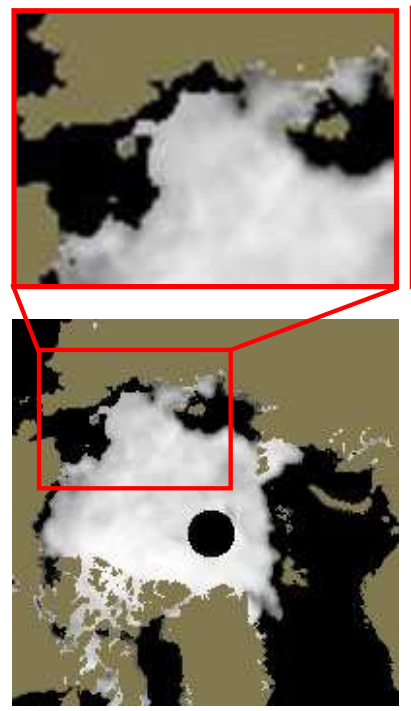

(a)SSM/I

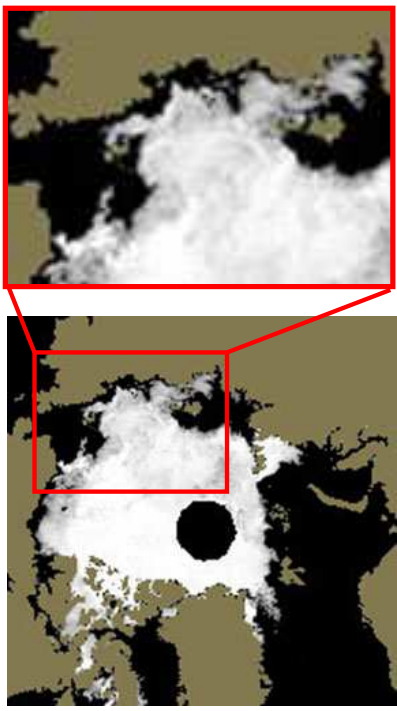

(b) AMSR2
Figure 4. Comparison of sea ice concentration images of SSM/I and ASMR2 (Arctic, July 27, 2013)

(The black hole around the north pole are data lack area due to the scanning limitation of sensors.) 


\subsection{MODIS data}

In order to verify the sea ice concentration calculated from ASMR2 data, optical sensor MODIS band $1 \& 2$ reflectance data (NASA, 2020) were used as reference. Among 36 bands of MODIS, only band $1 \& 2$ have the highest spatial resolution (IFOV) of $250 \mathrm{~m}$. Table 3 show the specifications of MODIS Band $1 \& 2$. In this study, the authors are using $25 \mathrm{~km}$ resolution AMSR2 sea ice concentration data. This means that pixel size of AMSR2 data corresponds to 100x100 pixels of MODIS data. Under the cloudless condition, much detailed distribution of sea ice can be observed from MODIS images. Since sea ice moves from time to time, simultaneous observation of different sensors is very important for the data comparison. Both Aqua and GCOM-W satellites are in the same orbital under the framework of the NASA's A-Train (NASA, 2012), the constellation of satellites, MODIS onboard Aqua observed the same area four minutes after the observation of AMSR2 onboard GCOM-W. Therefore, MODIS data is one of the most effective validation data for AMSR2 data. A MODIS image and an AMSR2 sea ice concentration image observed at the "same time" on February 27, 2013 are shown on Figure 5.

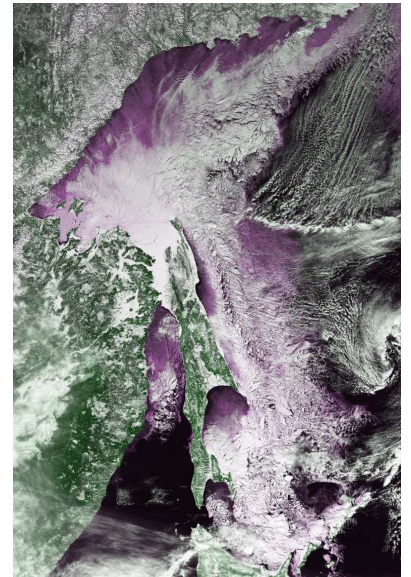

(a) MODIS image

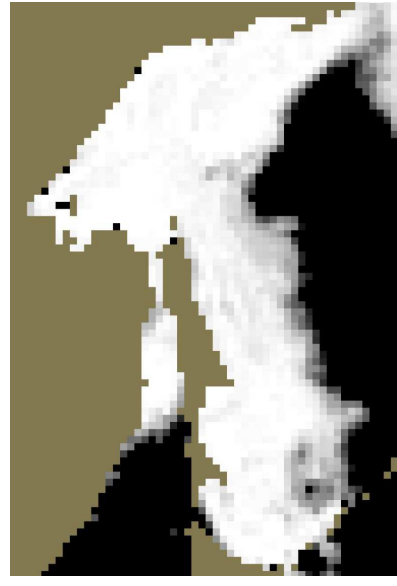

(b) AMSR2 IC image
Figure 5. Comparison of MODIS and AMSR2 images. (Sea of Okhotsk, February 27, 2013)

\section{TEST SITES}

The Sea of Okhotsk was selected as the test site of this study as shown on Figure 6. Since the Sea of Okhotsk is the southernmost sea ice zone in the Northern Hemisphere, the sun radiation is more intense than the other sea ice zones of the

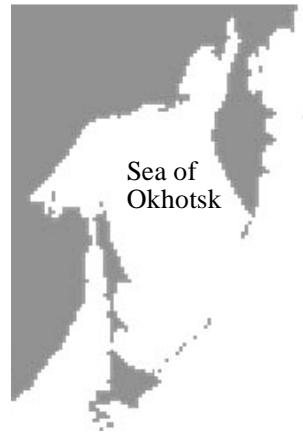

Figure 6. Test site : Sea of Okhotsk
Northern Hemisphere. Thus, it may be suitable for evaluating the threshold level of MODIS band 1 reflectance for discriminating sea ice from open water.

\section{ANALYSIS MEATHOD}

Figure 7 shows the procedure of evaluating AMSR2 sea ice concentration data using MODIS data. Firstly, MODIS Band 1 reflectance data were binarized to discriminate sea ice from open water. We define "binarize" as the conversion of each MODIS pixel to have a binary value either ice or water. Sea ice concentration for MODIS is calculated from each of the degraded MODIS data consisting of 100x100pixels that matches each AMSR2 pixel. Then the AMSR2 sea ice concentration of each pixel was compared with the sea ice concentration calculated from the matched MODIS data.

In this procedure, there is a need to select the appropriate threshold level to binarize each MODIS pixel. Even if the resolution of MODIS is much higher than that of AMSR2, the reflectance of one pixel of MODIS is the averaged reflectance of the mixture of sea ice and open water within the area of $250 \mathrm{~m} \times 250 \mathrm{~m}$. It is difficult to assess which reflectance is the correct threshold level to discriminate sea ice from open water.

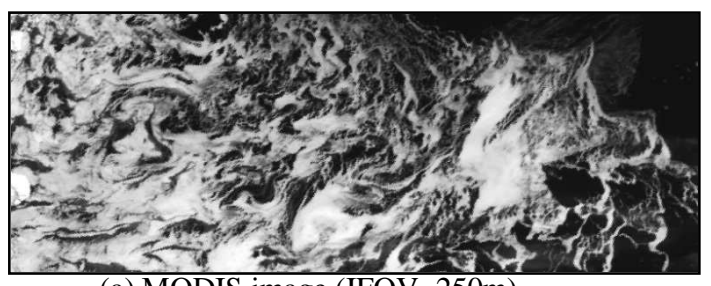

(a) MODIS image (IFOV $=250 \mathrm{~m})$

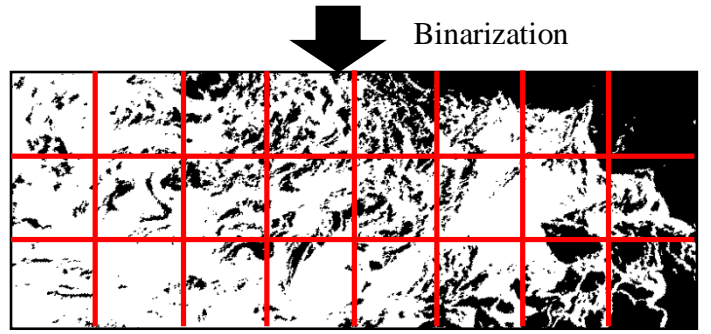

(b) Binarized MODIS image (IFOV=250m)

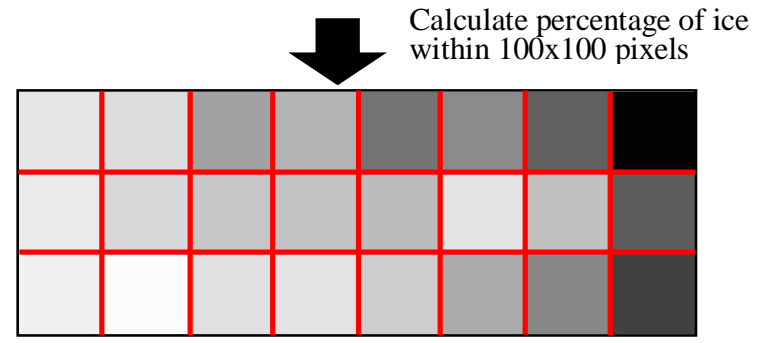

(c) MODIS ice concentration image (IFOV $=25 \mathrm{~km})$
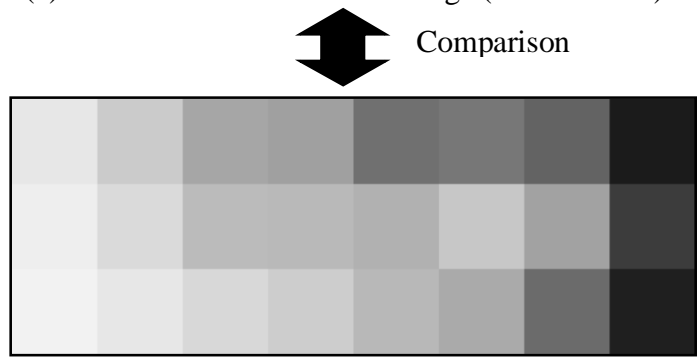

(d) AMSR2 sea ice concentration image (IFOV=25km) Figure 7. Procedure of evaluating AMSR2 sea ice concentration data using MODIS data. 
The authors have applied similar method for validating the accuracy of AMSR2 sea ice concentration data (Cho et al., 2019). In this study, the authors have investigated in details how the relationship between sea ice concentrations calculated from MODIS and AMSR2 change with the threshold level of MODIS data using RMSE. Figure 8 (a) and (b) show a pair of MODIS band 1 and AMSR2 IC image of a part of the Sea of Okhotsk observed on January 25, 2015. Figure 9 show how the MODIS IC image change as the threshold level (L) for binarization change. As the threshold level of MODIS band 1 reflectance increases, the ice area in the binarized MODIS image reduces and the MODIS ice concentration (IC) reduces accordingly. The RMSE between the AMSR2 IC and MODIS IC were calculated for each threshold level used for producing MODIS IC images. The relationship between RMSE and MODIS threshold level is shown on Figure 10.

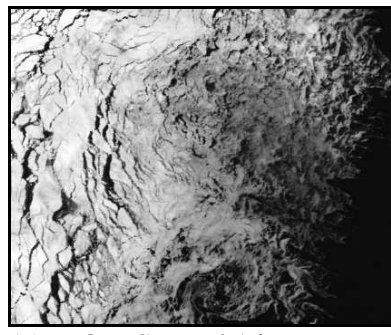

(a) MODIS Band 1 image (b) AMSR2 IC image

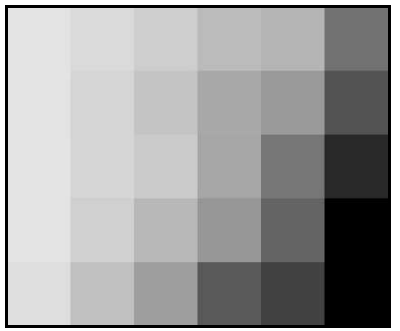

Figure 8. Comparison of MODIS band1 and AMSR2 IC images (Sea of Okhotsk observed on January 25, 2015)
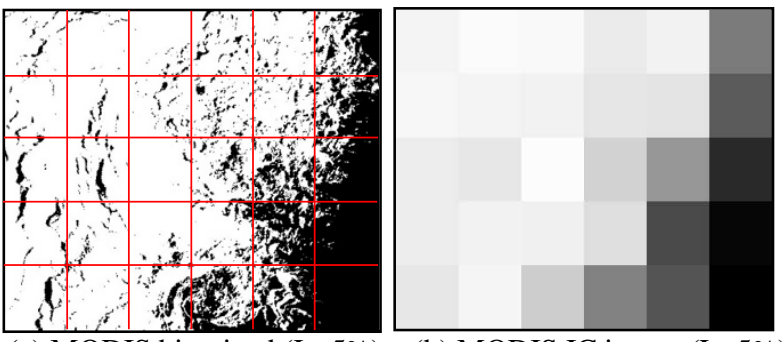

(a) MODIS binarized ( $\mathrm{L}=5 \%$ )

(b) MODIS IC image ( $\mathrm{L}=5 \%)$

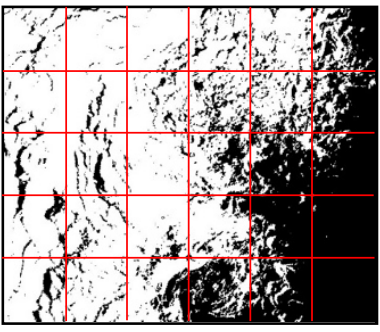

(c) MODIS binarized ( $\mathrm{L}=8 \%$ )

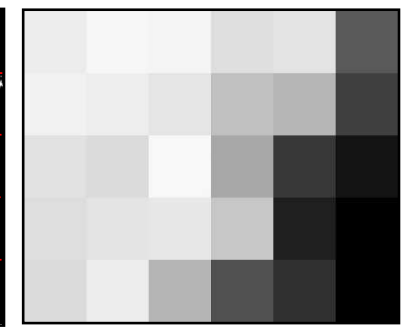

(d) MODIS IC image ( $\mathrm{L}=8 \%)$
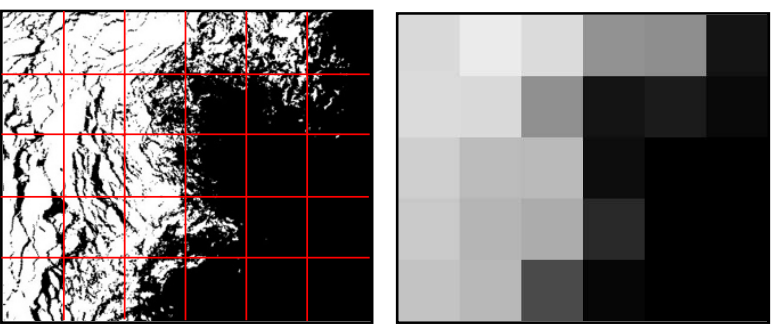

(e) MODIS binarized (L=15\%) (f) MODIS IC image ( $\mathrm{L}=15 \%)$ Figure 9. Comparison of MODIS binarized images and MODIS IC images with the change of threshold level. (Sea of Okhotsk observed on January 25, 2015)

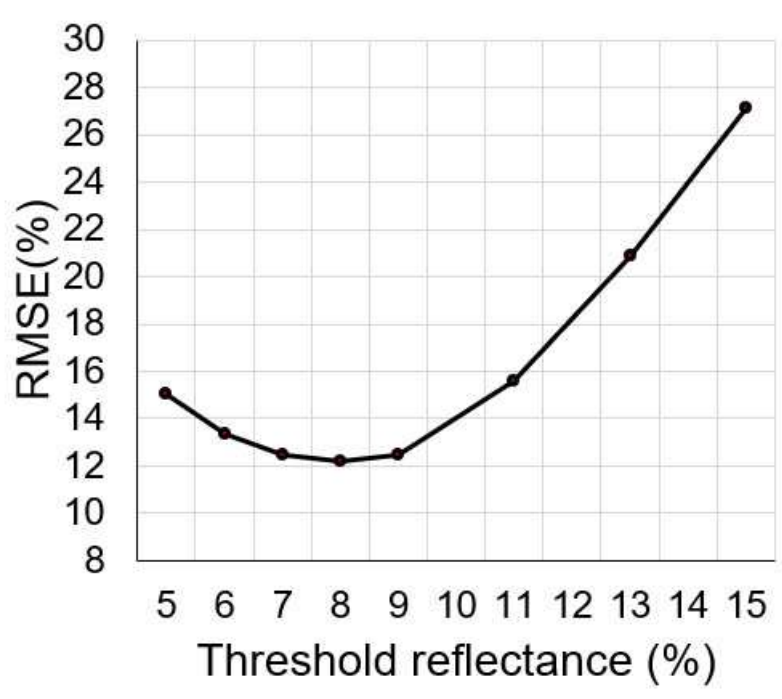

Figure 10. Relationship between RMSE and MODIS threshold level.

(Sea of Okhotsk observed on January 25, 2015)

Figure 10 shows that RMSE between AMSR2 IC and MODIS IC became minimum value of $12.3 \%$ when the threshold level for MODIS binarization was $8 \%$. In this study, the authors have used several threshold levels for calculating the RMSE between AMSR2 IC and MODIS IC, and have recorded the minimum RMSE as the RMSE of the AMSR IC image.

\section{RESULT}

The authors have validated the accuracy of AMSR2 IC data by comparing with MODIS IC for the total of eight scenes in the Sea of Okhotsk. Figure 11 to 15 show some of those examples and total result is shown on Table 4.
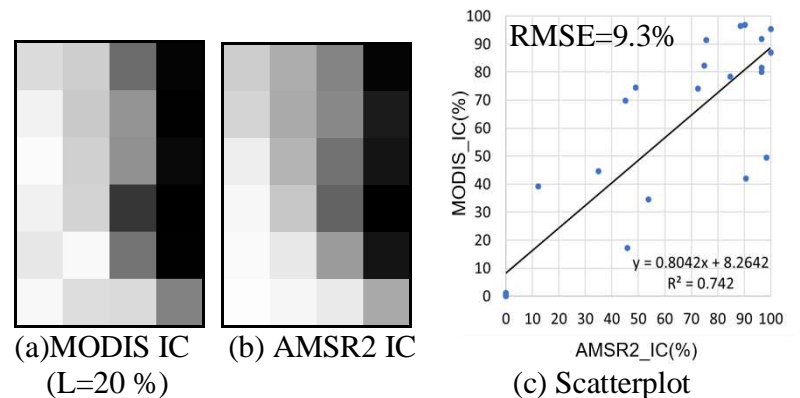

AMSR2_IC(\%)

(c) Scatterplot

Figure 11. Validation result of AMSR2 IC using MODIS IC (Sea of Okhotsk, Jan. 25, 2015)

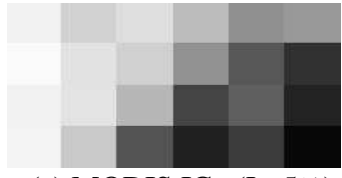

(a) MODIS IC $(\mathrm{L}=5 \%)$

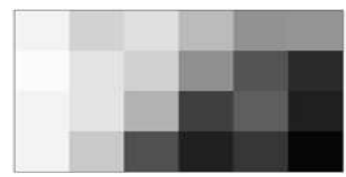

(b) AMSR2 IC (c) Scatterplot

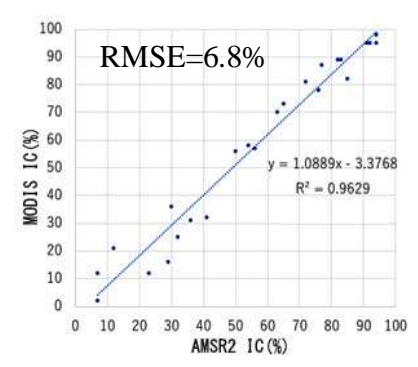

Figure 12. Validation result of AMSR2 IC using MODIS IC (Sea of Okhotsk, Mar. 14, 2015) 


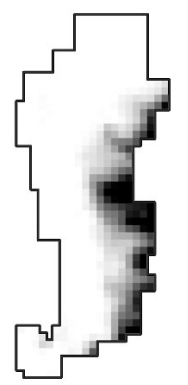

(a)MODIS IC

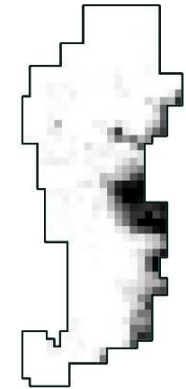

(b) AMSR2 IC

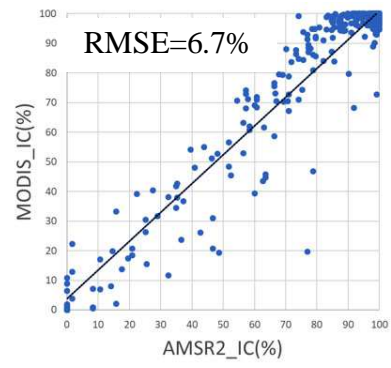

(c) Scatterplot
Figure 13. Validation result of AMSR2 IC using MODIS IC (Sea of Okhotsk, Mar. 13, 2016)

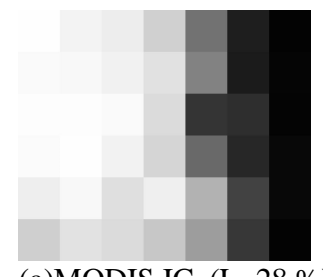

(a)MODIS IC ( $\mathrm{L}=28 \%)$

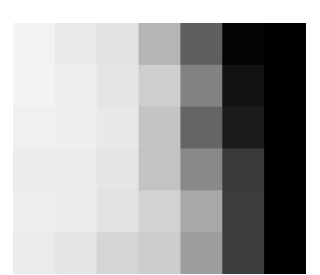

(b) AMSR2 IC

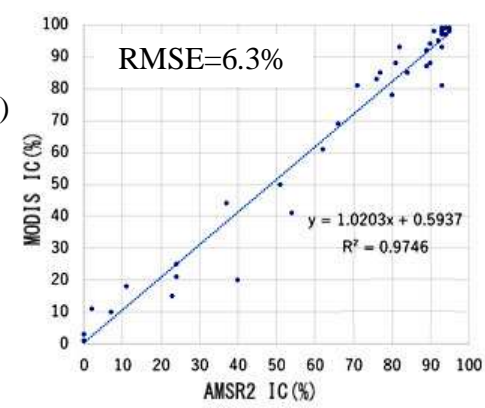

(c) Scatterplot
Figure 14. Validation result of AMSR2 IC using MODIS IC (Sea of Okhotsk, Jan. 1, 2017)

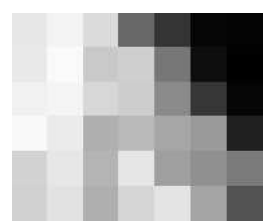

(a)MODIS IC ( $\mathrm{L}=10 \%)$

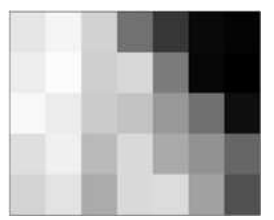

(b) AMSR2 IC

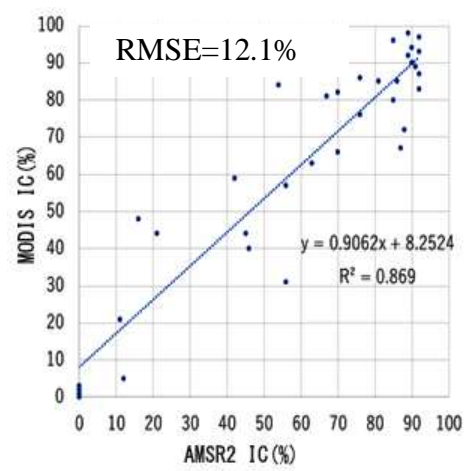

(c) Scatterplot
Figure 15. Validation result of AMSR2 IC using MODIS IC (Sea of Okhotsk, Mar. 28, 2019)

Table 3. Validation result of AMSR2 sea ice concentration in the Sea of Okhotsk

\begin{tabular}{|c|c|c|}
\hline Date & RMSE & Threshold Level (L) \\
\hline January 25, 2015 & $9.3 \%$ & $20 \%$ \\
\hline March 14, 2015 & $6.8 \%$ & $15 \%$ \\
\hline March 13, 2016 & $6.7 \%$ & $5 \%$ \\
\hline March 18, 2016 & $6.4 \%$ & $23 \%$ \\
\hline January 1, 2017 & $6.3 \%$ & $28 \%$ \\
\hline February 28, 2019 & $9.9 \%$ & $21 \%$ \\
\hline March 28, 2019 & $12.1 \%$ & $10 \%$ \\
\hline January 16, 2020 & $9.6 \%$ & $14 \%$ \\
\hline
\end{tabular}

\section{CONCLUSION}

In this study, the authors have evaluated the AMSR2 sea ice concentration data in details using MODIS data observed within few minutes after AMSR2 observation. The MODIS data were binarized to discriminate sea ice from open water, and sea ice concentration of each pixel size of AMSR2 were calculated using 100x100 pixels of the binarized MODIS data. By using the MODIS sea ice concentration as truth data, the RMSE of the AMSR2 ice concentration were calculated for a total of eight AMSR2 scenes in the Sea of Okhotsk. The RMSE were less than $10 \%$ in seven scenes, and RMSE of only one scene was $12.1 \%$. This result suggested that generally, sea ice concentration can be derived from AMSR2 data at a relatively good accuracy with RMSE of $10 \%$ or less.

The threshold level (L) of binarizing MODIS data was carefully selected by finding minimum RMSE between AMSR2 IC and MODIS IC. However, this does not mean that the threshold level used to calculate lowest RMSE is the best. This only tell us that the AMSR2 could not accurately detect sea ice when MODIS reflectance were lower than the threshold level. Ideally, the minimum reflectance of sea ice in MODIS images which can be identified with AMSR2 should be stable. However, as shown on Table 3, the optimum threshold reflectance for acquiring lowest RMSE changed from one scene to another. The possible reason of this variability could be the instability of MODIS reflectance of sea ice due to atmospheric effects, and the presence of different types of sea ice including new ice and grease ice. More studies are needed to identify the optimal threshold level to binarize MODIS data for calculating sea ice concentration.

\section{ACKNOWLEDGEMENTS}

This study was supported by JAXA under the framework of GCOM-W Project. The authors would like to thank JAXA for their kind support.

\section{REFERENCES}

JMA, 2020, Annual Anomalies of Global Average Surface Temperature (1891 - 2019), http://ds.data.jma.go.jp/tcc/tcc/ products/gwp/temp/ann_wld.html

NIPR, 2020, https://ads.nipr.ac.jp/vishop/\#/monitor

JAXA, 2012, http://suzaku.eorc.jaxa.jp/GCOM_W/w_amsr2/ whats_amsr2_j.html.

Comiso, J. C., 2009, Enhanced Sea Ice Concentrations and Ice Extent from AMSR-E Data, Journal of the Remote Sensing Society of Japan, Vol.29, No.1, pp.199-215.

Comiso, J. C., K. Cho, 2013, Description of GCOM-W1 AMSR2 Sea Ice Concentration Algorithm, Descriptions of GCOM-W1 AMSR2 Level 1R and Level 2 Algorithms, JAXA, NDX-120015A, (6)1-28, Available online:http://suzaku.eorc. jaxa.jp/ GCOM_W/data/doc/NDX-120015A.pdf

Comiso, J. C., 1995 ,SSM/I Sea Ice Concentrations Using the Bootstrap Algorithm", NASA Reference Publication 1380, Maryland, NASA Center for AeroSpace Information.

NASA, 2020, MODIS/AQUA Atmospherically Corrected Surface Reflectance 5-Min L2 Swath 250m, 500m, 1km, https://ladsweb.modaps.eosdis.nasa.gov/missions-andmeasurements/products/MYD09

NASA, 2012, Afternoon Constellation, http://atrain.nasa.gov/ Cho, K., R. Nagao, K. Naoki, 2019, Validation of AMSR2 sea ice concentration data using MODIS data, Int. Arch. Photogramm. Remote Sens. Spatial Inf. Sci., XLII-2/W13, 1741-1746, https://doi.org/10.5194/isprs-archives-XLII-2-W131741-2019. 